CLINICAL STUDY

\title{
Luteinizing hormone measurement in polycystic ovary syndrome: a practical approach
}

\author{
Christine Collet, Pierre Lecomte ${ }^{1}$, Denis Guilloteau, Bernard Lejeune ${ }^{2}$, Claire Lecomte ${ }^{1}$ and Jean-Claude Besnard \\ Service de Médecine Nucléaire and ${ }^{1}$ Service d'Endocrinologie, CHU Bretonneau, ${ }^{2}$ Laboratoire de Biophysique, Faculté de Pharmacie, Tours, France \\ (Correspondence should be addressed to C Collet, Service de Médecine Nucléaire In Vitro, Hôpital Bretonneau, 37044 Tours Cedex, France)
}

\begin{abstract}
The biological diagnosis of polycystic ovary syndrome (PCO) remains questionable, and a single immunological hLH (ihLH) determination can be misleading. In order better to characterize these patients, we studied hLH pulsatility every $10 \mathrm{~min}$ for $4 \mathrm{~h}$ using a radioimmunoassay and then compared the results with others we obtained with a biological method. Radioimmunological and biological profiles were similar in patients with PCO and in controls. We also studied pulsatility characteristics - frequency and amplitude - and calculated the area under the curve (AUC). There was no significant increase in frequency in our 10 patients with PCO but, as in other studies, increased amplitude of hLH pulses was observed. The most discriminating parameter was the AUC. For practical purposes, we propose that hLH in patients with PCO could be assessed efficiently by taking four samples every $10 \mathrm{~min}$, with computerized calculation of the AUC.
\end{abstract}

European Journal of Endocrinology 141 225-230

\section{Introduction}

The criteria for the diagnosis of polycystic ovary syndrome $(\mathrm{PCO})$ remain a matter of debate (1). Blood hormone measurements and ultrasound examination of the ovaries are both useful to confirm clinical suspicion of the disease. Hyperandrogenism and a high human luteinizing hormone (hLH) concentration compared with human follicle-stimulating hormone (hFSH) are cornerstones for the biochemical diagnosis (2). Hyperandrogenism and hirsutism, direct consequences of increased hLH, are frequent reasons for consultation, and it is necessary to obtain information on both hLH levels and biological hLH activity. Moreover, following Knobil's work (3), it has been accepted that pulsatile hLH is necessary for its biological action upon the ovaries. Therefore, as hLH concentrations vary considerably over time (4), a single measurement of basal hLH obtained by an immunological method (ihLH) is not enough to evaluate the true level of hLH hormonal secretion. Basal hLH values are often increased in PCO syndrome but, as initially described by Yen et al. (5), they are sometimes normal, particularly in obese patients with PCO. Various approaches have been described to evaluate such pulsatility in humans $(6,7)$. Nevertheless, despite their potency for research purposes, such approaches are not suitable for practical use. Contradictory results have been obtained concerning hLH pulsatility in PCO. Although an increase in amplitude is accepted, disagreements persist concerning an increase in pulse frequency. Increased frequency was observed by Waldstreicher et al. (8), Imse et al. (9) and Arroyo et al. (2), but was not found by Kazer et al. (10). Biological hLH activity (bhLH) has been found to be increased in PCO in all reported studies (11-13). However, the immunological methods used widely for clinical purposes are questionable for their ability to determine biological activity; indeed, the antibodies used in these assays do not necessarily recognize the hLH epitopes that are involved in the biological activity of hLH.

The aims of this study were to validate our immunological measurement of hLH, by evaluating biological activity at the same time, and to define the characteristics of hLH pulsatility in patients with PCO compared with normally ovulating controls. We suggest a practical and efficient biological method for the diagnosis of PCO.

\section{Subjects and methods}

\section{Subjects}

Ten patients with PCO were selected according to the following criteria: oligomenorrhoea and amenorrhoea, anovulatory cycles using a basal body temperature (BBT) chart, hirsutism using the clinical Ferriman and Gallway score, increased hLH and hLH/hFSH ratio $>2.5$. Four of ten patients with PCO presented with obesity defined by body mass index (BMI). Menses were induced by progesterone (dydrogesterone, $10 \mathrm{mg}$ for 5 days) after long-term amenorrhoea in two amenorrhoeic 
Table 1 PCO group: clinical characteristics and biological results.

\begin{tabular}{|c|c|c|c|c|c|c|c|c|c|c|c|}
\hline $\begin{array}{l}\text { Patient } \\
\text { no. }\end{array}$ & $\begin{array}{c}\text { Age } \\
(\mathrm{yr})\end{array}$ & Cycle & $\begin{array}{l}\text { Hirsutism } \\
\text { score }\end{array}$ & $\begin{array}{c}\text { BMI } \\
\left(\mathrm{kg} / \mathrm{m}^{2}\right)\end{array}$ & $\begin{array}{c}\text { And. } \\
(\mathrm{nmol} / \mathrm{l})\end{array}$ & $\begin{array}{l}\text { Test. } \\
(\mathrm{nmol} / \mathrm{l})\end{array}$ & $\begin{array}{l}\text { DHEAS } \\
(\mu \mathrm{mol} / \mathrm{l})\end{array}$ & $\begin{array}{l}\text { PRL } \\
(\mathrm{mlU} / \mathrm{l})\end{array}$ & $\begin{array}{c}\mathbf{F S H} \dagger \\
(\mathrm{IU} / \mathrm{I})\end{array}$ & $\begin{array}{l}\text { LH† } \\
\text { IU/I) }\end{array}$ & LH/FSH \\
\hline $\begin{array}{l}1 \\
2 \\
3 \\
4 \\
5 \\
6 \\
7 \\
8 \\
9 \\
10\end{array}$ & $\begin{array}{l}25.5 \\
32.5 \\
24 \\
25 \\
18 \\
30 \\
28 \\
30.5 \\
24 \\
31\end{array}$ & $\begin{array}{l}\text { O } \\
\text { O } \\
\text { A } \\
\text { O } \\
\text { O } \\
\text { O } \\
\text { A } \\
\text { A } \\
\text { A } \\
\text { O }\end{array}$ & $\begin{array}{r}7 \\
15 \\
10 \\
22 \\
13 \\
6 \\
9 \\
7 \\
6 \\
15\end{array}$ & $\begin{array}{l}21.3 \\
19.8 \\
26.6 \\
21.0 \\
18.5 \\
26.3 \\
21.0 \\
21.9 \\
24.4 \\
32.7\end{array}$ & $\begin{array}{r}9.3 \\
10.8 \\
10.1 \\
13.1 \\
8.0 \\
7.8 \\
12.3 \\
6.9 \\
8.6 \\
9.7\end{array}$ & $\begin{array}{l}1.1 \\
1.4 \\
2.2 \\
2.8 \\
1.9 \\
1.6 \\
0.7 \\
1.6 \\
2.1 \\
2.0\end{array}$ & $\begin{array}{l}2.6 \\
3.7 \\
8.3 \\
9.6 \\
4.4 \\
1.5 \\
3.7 \\
3.0 \\
2.6 \\
2.8\end{array}$ & $\begin{array}{l}150 \\
380 \\
230 \\
380 \\
200 \\
380 \\
320 \\
250 \\
210 \\
450\end{array}$ & $\begin{array}{l}7.2 \\
4.5 \\
4.1 \\
3.3 \\
7.6 \\
4.1 \\
4.7 \\
6.8 \\
4.0 \\
5.5\end{array}$ & $\begin{array}{l}17.0 \\
12.7 \\
16.0 \\
11.6 \\
18.0 \\
31.0 \\
14.5 \\
22.0 \\
16.0 \\
28.0\end{array}$ & $\begin{array}{l}2.4 \\
2.8 \\
3.9 \\
3.5 \\
2.4 \\
7.6 \\
3.1 \\
3.2 \\
4.0 \\
5.1\end{array}$ \\
\hline $\begin{array}{l}\text { Mean } \\
\text { S.D } \\
\text { Normal values }\end{array}$ & $\begin{array}{r}26.9 \\
4.4\end{array}$ & & $\begin{array}{c}11.0 \\
5.2 \\
<8\end{array}$ & $\begin{array}{c}23.4 \\
4.2 \\
21-23\end{array}$ & $\begin{array}{l}9.7 \\
2.0 \\
2.8-6.7\end{array}$ & $\begin{array}{l}1.7 \\
0.6 \\
0.6-1.6\end{array}$ & $\begin{array}{l}4.2 \\
2.6 \\
1.8-8.9\end{array}$ & $\begin{array}{l}295 \\
100 \\
115-480\end{array}$ & $\begin{array}{l}5.2 \\
1.5 \\
6-16\end{array}$ & $\begin{array}{l}18.7 \\
6.4 \\
2-10\end{array}$ & $\begin{array}{r}3.7 \\
1.6 \\
<2.5\end{array}$ \\
\hline
\end{tabular}

† Basal values. BMI, body mass index; And., androstenedione; Test., testosterone; PRL, prolactin O, oligomenorrhoea; A, amenorrhoea.

patients. Patients were evaluated on day 4 or 5 after menses to measure androgens (androstenedione, testosterone and dehydroepiandrosterone sulfate (DHEAS)), gonadotrophins (FSH and LH) and prolactin by appropriate RIA (Table 1). A gonadotropin-releasing hormone $(\mathrm{GnRH})$ test was performed to evaluate the hLH response when the basal LH/FSH ratio was less than 2.5. Ultrasound examination of the ovaries revealed the usual features of PCO in each patient: more than 10 follicles of $2-8 \mathrm{~mm}$ in diameter and an increase in stroma (14). Eight women with normal menstrual cycles and no clinical hirsutism were studied as controls on day 4 or 5 of the follicular phase. Normal cycles were evaluated using a biphasic BBT chart. None of the controls was obese. During the cycle when the study was performed, the duration of the luteal phase was at least 12 days and progesterone was more than $10 \mu \mathrm{g} / \mathrm{l}, 6$ or 7 days after the increase in temperature. Ultrasound examination revealed that the ovaries were normal.

Blood samples were drawn every $10 \mathrm{~min}$ for $4 \mathrm{~h}$ from ten patients and eight controls on day 4 or 5 starting at $0800 \mathrm{~h}$, while the woman was lying quietly. Aliquots of the 25 samples were frozen at $-20^{\circ} \mathrm{C}$ until measurements were performed to evaluate endogenous pulsatility. hLH was measured in the same 25 samples of five patients with PCO and four controls, by immunological (ihLH) and biological (bhLH) methods.

\section{Procedures}

hLH concentrations were determined using a commercially available radioimmunoassay $\left({ }^{125} \mathrm{I}-\mathrm{hLH}\right.$ COATRIA Biomerieux s.a., Marçy-l'Etoile, France) using a pair of monoclonal antibodies raised against different epitopes of $\alpha$ and $\beta$ subunits of hLH. The sensitivity of the assay was $0.8 \mathrm{IU} / \mathrm{l}$. Cross-reactivity with $\mathrm{hFSH}$ and human thyroid stimulating hormone was less than $0.1 \%$, and with human chorionic gonadotrophin it was less than
$0.00001 \%$. Intra-assay and interassay coefficients of variation were 3.9 and $5.2 \%$ respectively. Concentrations of hLH are expressed as 1st IRP MRC 68/40. The expected values of ihLH for the first half of the follicular phase determined in our laboratory are 2-10 IU/l. Serum bioactive hLH concentrations were determined by an in vitro bioassay based on the rat Leydig cell testosterone response to hLH standards and unknown samples, as previously described by Dufau et al. (15), with minor modifications (16). The sensitivity of the assay was $0.02 \mathrm{IU} / \mathrm{l}$. Interassay coefficients of variation were $32,18.5$ and $23.5 \%$ for three ihLH controls at $8.4,12.9$ and $46 \mathrm{IU} / \mathrm{l}$ respectively $(n=10)$. Intra-assay coefficients of variation were 14.2 and $13.6 \%$ for two bhLH concentrations at 62 and $311 \mathrm{IU} / \mathrm{l}$ respectively.

\section{Pulse analyses}

The presence of significant hLH secretory events was determined using the Munro program, which is based on the pulsar algorithm of Merriam \& Wachter (7). The parameters described by Baxter (17) were used to take into account the within-assay variance. These Baxter parameters, calculated by studying the duplicate values of all hLH standards used in 54 standard curves, were $\mathrm{B} 1=0.09984, \mathrm{~B} 2=0.02295, \mathrm{~B} 3=0.00002$. The parameters G2, G3 and G4 are those determined by Merriam and Wachter to obtain less than $5 \%$ of false-positive pulses: $\mathrm{G} 2=2.40, \mathrm{G} 3=1.68, \mathrm{G} 4=1.24$. For $\mathrm{G} 1$ and G5, we chose a high value arbitrarily equal to 30 , to eliminate false-positive pulses attributable to artefacts. Indeed, in view of the hLH half-life in plasma (more than $30 \mathrm{~min}$ ), an isolated increased hLH value is unlikely to be related to a hLH pulse, and a plateau with low hLH concentrations could not be considered as a physiological pulse. The other parameters of the Munro program are a smoothing window of 100 , a nadir window of $30 \mathrm{~min}$, a minimal pulse interval of $5 \mathrm{~min}$, and a rise threshold of 3 S.D. 


\section{Statistical analyses}

The differences between patient and control groups for each parameter studied were assessed by Student's $t$-test (a $P$ value less than 0.01 was selected as the limit of statistical significance), and the squared distance of Mahalanobis $\mathrm{D}^{2}$ (distance between the centres of the two groups). To perform comparison tests when the variance of each group was significantly different, we performed a logarithmic transformation.

\section{Results}

Immunological hLH measurements were performed in eight controls and ten patients with PCO every $10 \mathrm{~min}$ over $4 \mathrm{~h}$ (25 samples). ihLH measurements in controls ranged from 2.7 to $9.5 \mathrm{IU} / \mathrm{l}$ (ihLH maximum/ minimum ratio $=1.77$ ), mean $5.1 \pm 1.3 \mathrm{IU} / \mathrm{l}$, and those in patients with PCO from 2.5 to $31 \mathrm{IU} / \mathrm{l}$ (ihLH maximum $/$ minimum ratio $=1.97)$, mean $16.2 \pm$ 6.2 IU/l (Fig. 1). Biological hLH measurements were also performed in four controls and five patients with PCO every $10 \mathrm{~min}$ over $4 \mathrm{~h}$ (25 samples). bhLH measurements in controls ranged from 10 to $33 \mathrm{IU} / \mathrm{l}$ (bhLH maximum/minimum ratio $=1.76$ ), mean $21.1 \pm 3.3 \mathrm{IU} / \mathrm{l}$ and those in patients with PCO from 19 to $259 \mathrm{IU} / \mathrm{l}(\mathrm{bhLH}$ maximum/minimum ratio $=3.19$ ), mean $106.5 \pm 48.8 \mathrm{IU} / \mathrm{l}$. The calculated bhLH/ihLH $(\mathrm{B} / \mathrm{I})$ ratio was $4.4 \pm 0.7$ in controls $(n=4)$ and $8.4 \pm 1.5$ in patients with $\mathrm{PCO}(n=5)$.

The profiles of bhLH and ihLH measured in four controls and five patients with PCO were compared. Several methods of pulse analysis exist, but no single method is regarded as standard (18-20), and we chose visual pulse detection as an efficient method with which to compare biological and immunological assay data for LH. The same immunological and biological profiles were observed visually in control individuals and patients with PCO (Fig. 2). ihLH pulse analysis was performed with the Munro algorithm in eight controls and ten patients with PCO. Over $4 \mathrm{~h}$, the number of pulses was $3.0 \pm 0.8$ in controls and $3.5 \pm 1.4$ in patients with PCO, pulse amplitude was $1.9 \pm 0.6 \mathrm{IU} / \mathrm{l}$ in controls and $5.5 \pm 2.2 \mathrm{IU} / \mathrm{l}$ in those with PCO, and AUC was $120 \pm 56 \mathrm{IU} / \mathrm{l}$ in controls and $504 \pm 116 \mathrm{in}$ those with PCO (Fig. 3). The statistical analysis of ihLH characteristics in control $(n=8)$ and in PCO $(n=10)$ populations is summarized in Table 2. All parameters were significant in discriminating between patients with PCO and controls $(P<0.001)$ : mean ihLH, maximum ihLH, and parameters resulting from the Munro pulsatility study (amplitude of pulses and AUC) except the number of pulses $(P=0.387)$. The highest $\mathrm{D}^{2}$ was found for maximum ihLH and AUC parameters. There were no 'misclassified' cases using these two parameters. In order to reduce the cost of the exploration, we studied the efficiency of the AUC parameter to discriminate between patients with $\mathrm{PCO}$ and controls

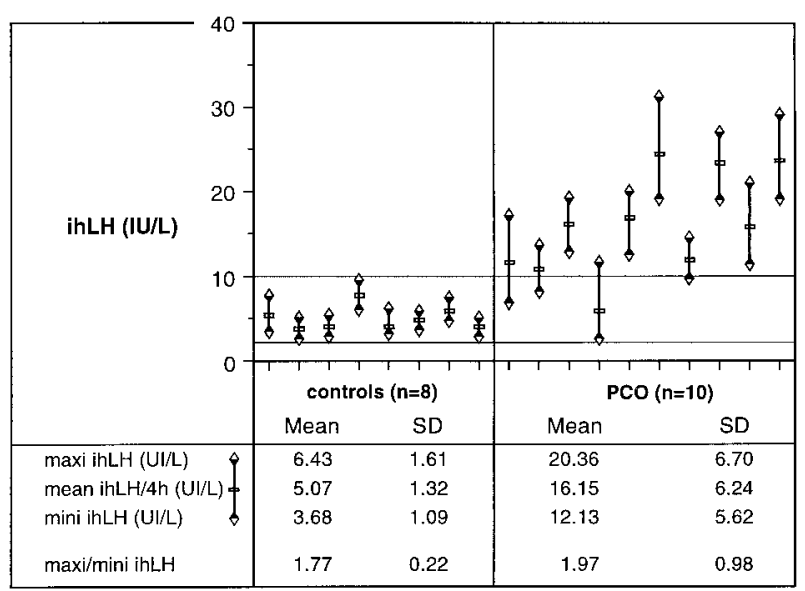

Figure $1 \mathrm{Immunological} \mathrm{hLH}$ results in control and PCO groups. Normal concentrations during the follicular phase are indicated by the grey area $(2-10 \mathrm{IU} / \mathrm{I})$.
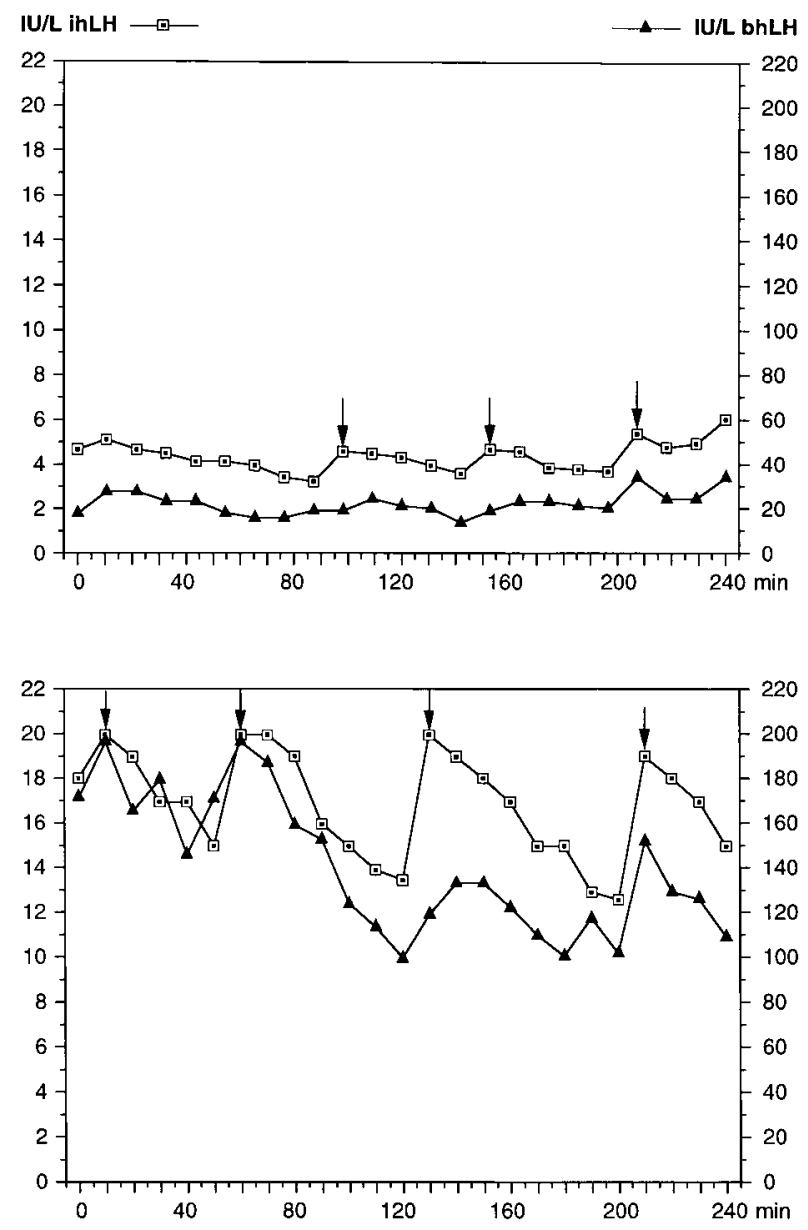

Figure $2 \mathrm{Immunological}$ and biological hLH profiles obtained in one control (top) and one patient with PCO (bottom). The arrows indicate immunological $\mathrm{hLH}$ pulses detected by the Munro program. 


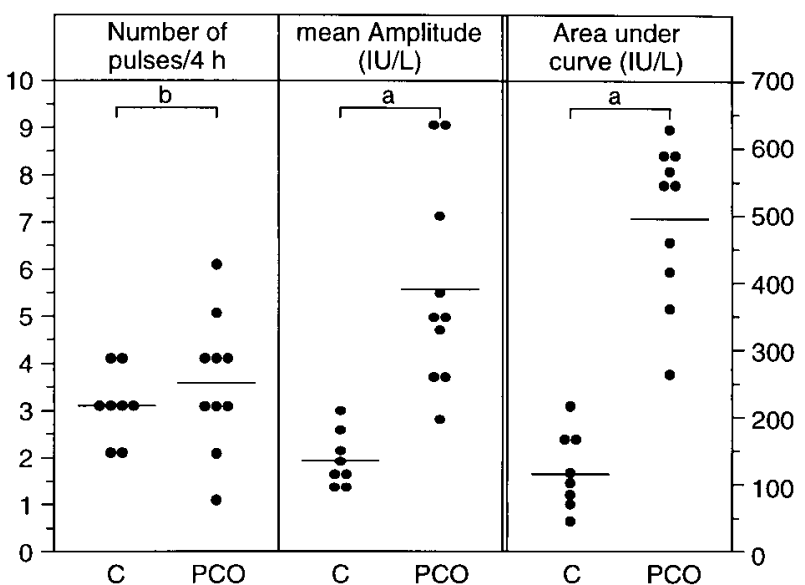

Figure $3 \mathrm{Immunological}$ hLH pulsatility parameters in eight controls (C) and ten patients with PCO. The mean values in each group are indicated by a line. a: $\mathrm{P}<0.001$; b: not significant.

according to the duration of sampling. We chose a short period (sampling every $10 \mathrm{~min}$ over $30 \mathrm{~min}$ ) and obtained very good discrimination between the two groups with mean hLH concentrations $(t=7.59, P<$ $\left.0.001, \mathrm{D}^{2}=14.03\right)$ and $\mathrm{AUC}\left(t=7.62, P<0.001, \mathrm{D}^{2}=\right.$ 14.12), whatever the starting time of the evaluation (data not shown).

\section{Discussion}

\section{Validation of immunological measurements}

Our first objective was to validate our immunological measurement of hLH. It is important to recognize biologically active molecules when hLH concentrations are being measured. Figure 2 shows examples of similar hLH profiles over the $4 \mathrm{~h}$ with both biological and immunological methods. In common with others $(9,13$, 21), we observed some dissociation of biological and immunological hLH profiles - sometimes with a delay in the occurrence of biological pulses compared with immunological pulses $( \pm 10-20 \mathrm{~min})$ both in controls and in patients with PCO, which might perhaps reflect a maturation process - and additional biological pulses (more often than immunological pulses) with low amplitude, explained in part by amplification of the biological signal. We compared biological and immunological results by means of the $\mathrm{B} / \mathrm{I}$ ratio. In patients with $\mathrm{PCO}$, this ratio was double that in controls and it increased at the time of pulses in both populations. These two findings suggest that hLH isoforms with greater biological activity are observed in patients with PCO than in controls $(13,22)$, and at the time of pulses in both controls and patients with PCO (23). These results would support the hypothesis that some immunological epitopes recognized by our immunoassay kit are involved in the biological activity. This should mean that this immunoassay (Biomerieux kit) could be used as a simple method to detect biologically active hLH, as there is, to date, no immunological method able to recognize all the epitopes involved in the biological activity $(9,24)$.

It is generally accepted that hLH can be in the normal range in $\mathrm{PCO}$ when a single random hLH determination is made $(25,26)$. In this case, it has been suggested that a GnRH stimulation test should be performed to evaluate the explosive hLH response. Different hypotheses have been put forward to explain the increase in basal hLH concentration in PCO. Murdoch et al. (27) suggested that, in PCO, there could be delayed metabolic clearance of hLH and that spontaneous secretion of hLH may be increased independently of GnRH stimulation. Imse et al. (9) suggested that, in PCO, there could be pulses of immunoreactive, but biologically inactive, hLH. In spite of a selection of patients with PCO in our pulsatile evaluation (Fig. 1), we observed variability of ihLH concentrations. The ihLH range in controls was from 2.7 to $9.5 \mathrm{IU} / \mathrm{l}$ over $4 \mathrm{~h}$, in agreement with our laboratory reference values $(2-10 \mathrm{IU} / \mathrm{l})$. In patients with PCO, ihLH concentrations ranged from 2.5 to $31 \mathrm{IU} / \mathrm{l}$. In four of ten patients with PCO, the lowest ihLH values observed were in the same range as those in controls (Fig. 1). In contrast, we observed that

Table 2 Evaluation of different inLH parameters for diagnosis of PCO, based on a comparison of eight controls and ten patients with $\mathrm{PCO}$.

\begin{tabular}{|c|c|c|c|c|c|}
\hline & \multirow[b]{2}{*}{$\underset{(I U / I)}{\text { Mean ihLH }}$} & \multirow[b]{2}{*}{$\begin{array}{l}\text { Max. ihLH } \dagger \\
(I U / I)\end{array}$} & \multicolumn{3}{|c|}{ Munro program } \\
\hline & & & $\begin{array}{l}\text { Number of } \\
\text { pulses } / 4 \mathrm{~h}\end{array}$ & $\begin{array}{l}\text { Pulse } \\
\text { amplitude } † \\
\text { (IU/I) }\end{array}$ & $\begin{array}{c}\mathrm{AUC} \dagger \\
(\mathrm{IU} / \mathrm{I})\end{array}$ \\
\hline \multicolumn{6}{|l|}{ Student's $t$-test } \\
\hline$\stackrel{t}{P}$ & $\begin{array}{r}6.410 \\
<0.001\end{array}$ & $\begin{array}{r}8.096 \\
<0.001\end{array}$ & $\begin{aligned} & 0.889 \\
= & 0.387\end{aligned}$ & $\begin{array}{r}6.201 \\
<0.001\end{array}$ & $\begin{array}{r}8.162 \\
<0.001\end{array}$ \\
\hline $\begin{array}{l}\text { Squared distance } \\
\text { of Mahalanobis }\left(D^{2}\right)\end{array}$ & 9.245 & 14.748 & 0.178 & 8.652 & 14.99 \\
\hline
\end{tabular}

$\dagger \mathrm{t}, P$ and $D^{2}$ after parameter log transformation. 
maximum hLH concentrations were always more than $10 \mathrm{IU} / \mathrm{l}$. One patient with PCO (No. 4) was of special interest, as she appeared to be misclassified according to the mean ihLH and number of pulses. Clinical and biological criteria for PCO were fulfilled: oligomenorrhoea, hirsutism, anovulation (without obesity), increased basal ihLH (11.6) in relation to hFSH (3.3) and increased androgens, in particular androstenedione and DHEAS (Table 1). Analysis of ihLH pulsatility revealed a single huge amplitude pulse. This patient presented the lowest minimum ihLH concentration, similar to those in controls, and low mean ihLH. Two pregnancies were achieved in this patient with induction of ovulation, the first with purified urinary hFSH after clomiphene treatment failed, the second with clomiphene. The patient is still oligomenorrhoeic and her hirsutism is currently being treated with cyproterone acetate. This case illustrates the wide variability of presentation of PCO syndrome and the difficulties of biological classification. A single random hLH determination can therefore be misleading for diagnosis of PCO.

\section{Discrimination between patients with PCO and normal individuals}

Pulsatile analysis has been suggested as a method that is able clearly to separate patients with PCO and normal subjects, which was the second objective of this study. Three parameters were studied: frequency, amplitude and AUC (Fig. 3). The number of pulses in our PCO population was highly heterogenous, from one to six pulses $/ 4 \mathrm{~h}$, but the mean pulse frequency showed no significant differences between patients with $\mathrm{PCO}$ and controls $\left(P=0.387, D^{2}=0.178\right)$. Interval mean pulses in the control group $(77.5 \pm 12.9 \mathrm{~min})$ and in the PCO group $(76.9 \pm 58.7 \mathrm{~min})$ were almost the same. A high level of controversy regarding pulsatile analysis persists in the literature. For instance, our results agree with those of Kazer et al. (10), but not with those published by Waldstreicher et al. (8) and Taylor et al. (26). The discrepancy can be explained by several factors: (a) heterogeneity of PCO syndrome $(1,28,29)$ - it is well known that induction of ovulation is difficult in hyperpulsatile patients, whereas normal pulsatility is less frequently observed and easier to treat; (b) day of cycle studied $(21,30,31)$ and time of day (32); (c) progesterone pretreatment in oligo- or amenorrhoea PCO (12); (d) duration and rhythm of blood sampling $(26,33,34)$; (e) methods used for both hLH immunoassays (kit calibration, epitope specificities of the monoclonal antibodies) $(35,36)$ and hLH bioassays (testicular preparation, calibration) $(16,35)$; (f) different algorithms used in pulse analysis $(33,34)$.

Increased hLH pulse amplitude has been described by all authors to distinguish between patients with PCO and controls. In our study, this second parameter was significantly different in patients with PCO compared with controls. However, one patient was 'misclassified' using this single parameter. Moreover, obesity has to be taken into account, as it has recently been shown to induce a decrease in pulse amplitude $(2,26)$. We observed a similar negative effect of increased weight upon amplitude (result not shown).

AUC, the third parameter we studied, was the most significant $\left(\mathrm{D}^{2}=14.99\right.$ for the $\log$ of $\left.\mathrm{AUC}\right)$, and no misclassification was observed with this approach. In our study, therefore, AUC seems to be the best parameter with which to diagnose PCO syndrome clearly; however, this parameter was evaluated on the basis of 25 samples (4h).

\section{Clinical diagnosis of PCO}

Our third objective was to find a practical and efficient method of clinical diagnosis of PCO. We therefore calculated mean hLH level and AUC for 3, 2, 1 and $0.5 \mathrm{~h}$, with sampling every $10 \mathrm{~min}$. Very good results $(P<0.001)$ were obtained with $30 \mathrm{~min}$ of sampling (four samples). For practical purposes, we propose that hLH should be assessed over $30 \mathrm{~min}$, using four samples taken at 10-min intervals, and to determine the AUC mathematically using a standard computer program. We have verified that our proposition is valid whatever the starting time of the evaluation. This proposition for the clinical diagnosis of PCO must be compared with those from other studies: Santen and Bardin (6) suggested that nine samples allowed a good estimation of mean hLH; Manieri et al. (37) evaluated the LH/FSH ratio with results obtained on pooled sera from four samples every $30 \mathrm{~min}$; Arroyo et al. (2) proposed studying hLH in patients with PCO using only two samples (0 and $30 \mathrm{~min})$.

\section{Conclusion}

We have confirmed that the immunoassay used in this study recognized biologically active hLH, and therefore this method seems to be very appropriate for clinical application. However, a single determination of the hLH concentration with this immunoassay failed, in some cases, correctly to diagnose PCO. The study of hLH pulsatility characteristics has been proposed to overcome this problem. High hLH pulsatility frequency has recently been confirmed in the literature $(2,26)$, but very extreme conditions are required. In this study, we have demonstrated that, in contrast to frequency, the AUC is a very potent parameter with which to discriminate between patients with PCO and controls, without overlap. Moreover, this reliable method seems to remain valid when the sampling duration is shortened to $30 \mathrm{~min}$.

\section{References}

1 Franks S. Medical progress: polycystic ovary syndrome (Review article). New England Journal of Medicine 1995333 853-861. 
2 Arroyo A, Laughlin GA, Morales AJ \& Yen SSC. Inappropriate gonadotropin secretion in polycystic ovary syndrome: influence of adiposity. Journal of Clinical Endocrinology and Metabolism 199782 3728-3733.

3 Knobil E. The neuroendocrine control of the menstrual cycle. Recent Progress in Hormonal Research 198036 53-88.

4 Midgley AR \& Jaffe RB. Regulation of human gonadotropins. IV: Correlation of serum concentrations of follicular stimulating hormone and luteinizing hormone during the menstrual cycle. Journal of Clinical Endocrinology 196828 1699-1703.

5 Yen SSC, Vela P \& Rankin J. Inappropriate secretion of folliclestimulating hormone and luteinizing hormone in polycystic ovarian disease. Journal of Clinical Endocrinology $197030435-$ 442.

6 Santen RJ \& Bardin CW. Episodic luteinizing hormone secretion in man. Pulse analysis, clinical interpretation, physiologic mechanisms. Journal of Clinical Investigation 197352 26172628.

7 Merriam GR \& Wachter KW. Algorithms for the study of episodic hormone secretion. American Journal of Physiology 1982243 E310-E318.

8 Waldstreicher J, Santoro NF, Hall JE, Filicori M \& Crowley Jr WF Hyperfunction of the hypothalamic-pituitary axis in women with polycystic ovarian disease: indirect evidence for partial gonadotroph desensitization. Journal of Clinical Endocrinology and Metabolism 198866 165-172.

9 Imse V, Holzapfel G, Hinney B, Kuhn W \& Wuttke W. Comparison of luteinizing hormone pulsatility in the serum of women suffering from polycystic ovarian disease using a bioassay and five different immunoassays. Journal of Clinical Endocrinology and Metabolism 199274 1053-1061.

10 Kazer RR, Kessel B \& Yen SSC. Circulating luteinizing hormone pulse frequency in women with polycystic ovary syndrome. Journal of Clinical Endocrinology and Metabolism 198765 233236.

11 Lobo RA, Kletzky OA, Campeau JD \& DiZerega GS. Elevated bioactive luteinizing hormone in women with the polycystic ovary syndrome. Fertility and Sterility 198339 674-678.

12 Anttila L, Ding YQ, Ruutiainen K, Erkkola R, Irjala K \& Huhtaniemi I. Clinical features and circulating gonadotropin, insulin and androgen interactions in women with polycystic ovarian disease. Fertility and Sterility 199155 1057-1061.

13 Fauser BCJM \& DeJong FH. Gonadotropins in polycystic ovarian syndrome. Annals of the New York Academy of Sciences 1993687 $150-161$

14 Kyei-Mensah A, Zaidi J \& Campbell S. Ultrasound diagnosis of polycystic ovary syndrome. Baillière's Clinical Endocrinology and Metabolism 199610 249-262.

15 Dufau ML, Mendelson CR \& Catt KJ. A highly sensitive in vitro bioassay for luteinizing hormone and chorionic gonadotropin: testosterone production by dispersed Leydig cells. Journal of Clinical Endocrinology and Metabolism 197439 610-613.

16 Revol A, Carreau S, Castanier M, Collet C, Denis I, Guilloteau D et al. Mesure de l'activité biologique de la hLH. Etude multicentrique. Annales de Biologie Clinique 199755 123-128.

17 Baxter RC. Simplified approach to confidence limits in radioimmunoassay. Clinical Chemistry 198026 763-765.

18 Veldhuis JD \& Johnson ML. Cluster analysis: a simple, versatile, and robust algorithm for endocrine pulse detection. American Journal of Physiology 1986243 E486-E493.

19 Royston JP. The statistical analysis of pulsatile hormone secretion data. Clinical Endocrinology 198930 201-210.

20 Schweizer MWF, Walter-Sack I, Rabe TN \& Runnebaum B. Basal and pulsatile secretion of human luteinizing hormone. New methods for analysis of endocrine secretion processes. Experimental and Clinical Endocrinology and Diabetes $1996104235-$ 242 .

21 Veldhuis JD, Beitins IZ, Johnson ML, Serabian MA \& Dufau ML. Biologically active luteinizing hormone is secreted in episodic pulsations that vary in relation to stage of the menstrual cycle.
Journal of Clinical Endocrinology and Metabolism 198458 10501058.

22 Ding YQ \& Huhtaniemi I. Preponderance of basic isoforms of serum luteinizing hormone (LH) is associated with the high bio/ immuno ratio of $\mathrm{LH}$ in healthy women and in women with polycystic ovarian disease. Human Reproduction 19916 346-350.

23 Veldhuis JD, Johnson ML \& Dufau ML. Preferential release of bioactive luteinizing hormone in response to endogenous and low dose exogenous gonadotropin-releasing hormone pulses in man. Journal of Clinical Endocrinology and Metabolism 198764 12751282.

24 Niccoli P, Costagliola S, Patricot MC, Mallet B, Benhamed M \& Carayon P. European collaborative study of luteinizing hormone assay: 3. Relationship of immunological reactivity, biological activity and charge of human luteinizing hormone. Journal of Endocrinological Investigation 199619 260-267.

25 Fauser BCJM, Pache TD, Hop WCJ, de Jong FH \& Dahl KD. The significance of a single serum LH measurement in women with cycle disturbances: discrepancies between immunoreactive and bioactive hormone estimates. Clinical Endocrinology 199237 445-452.

26 Taylor AE, McCourt B, Martin KA, Anderson EJ, Adams JM, Schoenfeld D et al. Determinants of abnormal gonadotropin secretion in clinically defined women with polycystic ovary syndrome. Journal of Clinical Endocrinology and Metabolism 1997 $822248-2256$.

27 Murdoch AP, Diggle PJ, White MC, Kendall-Taylor P \& Dunlop N. LH in polycystic ovary syndrome: reproducibility and pulsatile secretion. Journal of Endocrinology 1989121 185-191.

28 Gadir AA, Khatim MS, Mowafi RS, Alnaser HMI, Alzaid HGN \& Shaw RW. Polycystic ovaries: do these represent a specific endocrinopathy? British Journal of Obstetrics and Gynaecology 199198 300-305.

29 Graf MA, Bielfeld P, Pistler W, Weiers C \& Kûhn-Velten WN. Pulsatile luteinizing hormone secretion pattern in hyperandrogenemic women. Fertility and Sterility 199359 761-767.

30 Minakami H, Abe N, Izumi A \& Tamada T. Serum luteinizing hormone profile during the menstrual cycle in polycystic ovarian syndrome. Fertility and Sterility 198850 990-992.

31 Filicori M \& Flamigni C. Physiology and pathophysiology of pulsatile gonadotropin secretion. Gynecological Endocrinology $1988273-85$.

32 Venturoli S, Porch E, Fabbri R, Magrini O, Gammi L, Paradisi R et al. Episodic pulsatile secretion of FSH, LH, prolactin, oestradiol, oestrone and LH circadian variations in polycystic ovary syndrome. Clinical Endocrinology 198828 93-107.

33 Lejeune H, Billion P, Charrié A, Fleury MC, El Midani M, Tourniaire J et al. Technology of luteinizing hormone (LH) pulse analysis. In Recent Progress on GnRH and Gonadal Peptides. Eds P Bouchard, F Haour, P Franchimont \& B Schatz. Paris: Elsevier, 1990.

34 Richard JL, Bringer J, Daurès JP, Parer-Richard C, Jaffiol C \& Mirouze J. Méthodes d'analyse de la pulsatilité hormonale. Annales d'Endocrinologie 199051 181-193.

35 Jeffcoate SL. Analytical and clinical significance of peptide hormone heterogeneity with particular reference to growth hormone and luteinizing hormone in serum. Clinical Endocrinology 199338 113-121.

36 Costagliola S, Niccoli P, Florentino M \& Carayon P. European collaborative study of luteinizing hormone assay: 2. Discrepancy among assay kits is related to variation both in standard curve calibration and epitope specificity of kit monoclonal antibodies. Journal of Endocrinological Investigation 199417 407-416.

37 Manieri C, Pastorino R, Marolda AR, Musso M, Boggio G et al. A new approach in the evaluation of gonadotropins for the diagnosis of polycystic ovary syndrome. Panminerva Medica $199537115-118$.

Received 18 November 1998

Accepted 31 May 1999 